\title{
Extensive cerebellar necrosis
}

\author{
Bharat Hosur, ${ }_{1}^{01}$ Sameer Vyas, ${ }^{1}$ Lokesh Saini, ${ }^{2}$ Shivan Kesavan ${ }^{2}$
}

${ }^{1}$ Radiodiagnosis, Post Graduate Institute of Medical Education and Research, Chandigarh, India ${ }^{2}$ Pediatrics, Post Graduate Institute of Medical Education and Research, Chandigarh, India

Correspondence to Dr Sameer Vyas, sameer574@yahoo.co.in

Accepted 18 May 2019

\section{DESCRIPTION}

A developmentally normal, previously well 1-year-old girl presented with altered sensorium, 4 days after the onset of an episode of acute gastroenteritis. She had features of raised intracranial pressure and was in hypotensive shock at the time of admission. Investigations revealed mild thrombocytopenia; however, cerebrospinal fluid analysis, blood cultures and serologies for infections were unyielding. She required a ventriculoperitoneal shunt, mechanical ventilation and vasopressor support, following which gradual improvement in sensorium ensued. However, motor deficits persisted and the child was discharged after 3 weeks on a tracheostomy. Neuroimaging at the time of discharge (figure 1) revealed bilaterally symmetrical cerebellar involvement with no abnormal foci of contrast enhancement. At 1-year follow-up, MRI of the brain (figure 2), showed persistence of non-progressive, non-enhancing isolated cerebellar necrosis with the child showing mild improvement of residual motor deficits.

Diffuse cerebellar necrosis has been previously documented in a few case reports pertaining to conditions like postradiation necrosis, ${ }^{1}$ posthypoxia ${ }^{2}$ and systemic sclerosis, ${ }^{3}$ and is usually associated with brainstem involvement. Preferential necrosis of cerebellar tonsils due to coning is also documented in patients who underwent multiple lumbar punctures. ${ }^{4}$ Unlike the well-studied postinfective striatal necrosis

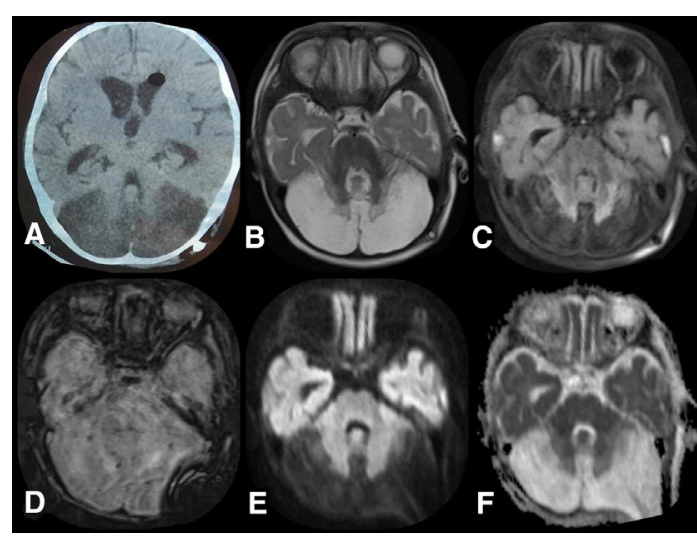

Figure 1 Initial brain imaging (postventriculoperitoneal shunt): Non-contrast CT (A) showing bilaterally symmetrical cerebellar hypodensities, mild diffuse ventriculomegaly with pneumoventricle; MRI-axial T2 weighted (B), FLAIR (C), susceptibility weighted (D), diffusion (at $b=1000 \mathrm{~s} / \mathrm{mm}^{2}$ ) weighted (E) and apparent diffusion coefficient (F), showing bilaterally symmetrical non-restricting T2 hyperintensities with no significant susceptibility changes. Artefacts in relation to left cerebellar hemisphere (D-F) are due to ventriculoperitoneal shunt tube.

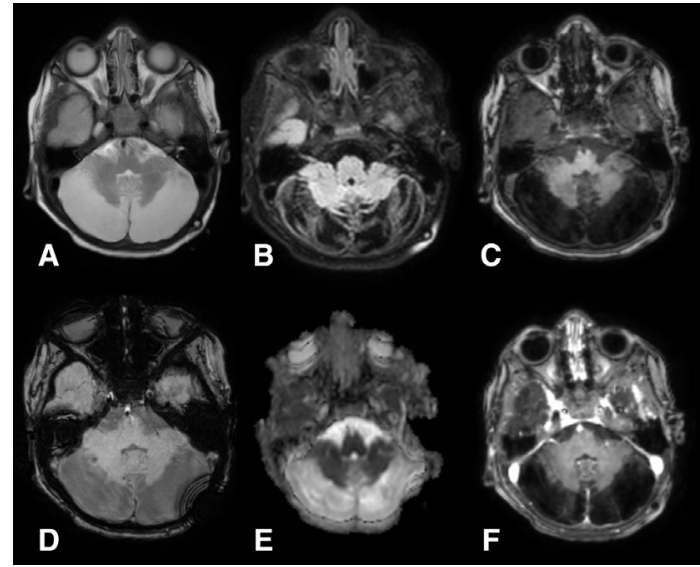

Figure 2 One-year follow-up MRI brain—axial T2 weighted (A), FLAIR (B), T1 weighted (C), susceptibility weighted (D), apparent diffusion coefficient (E) and contrast-enhanced T1 weighted (F) images showing, persisting non-progressive bilaterally symmetrical cerebellar T2 and FLAIR hyperintensities without restriction of diffusion and absence of contrast enhancement or susceptibility changes.

in children, ${ }^{5}$ the isolated extensive bilateral cerebellar necrosis of infective aetiology is hitherto unreported. Although, no precise neuroinfection could be established histopathologically or serologically in our case; clinicoradiological correlation points to the acute cerebellitis as a primary working diagnosis. Lack of clinical markers and presence of persistent bilaterally symmetrical cerebellar involvement rules out focal causes like dysplastic cerebellar gangliocytoma, crossed cerebellar diaschisis and cerebellar tumours. Relative sparing of cerebellar vermis and peduncles as well as brainstem may explain the relatively preserved clinical status in our case. Further follow-up of the patient with neurological examination and neuraxial imaging may open newer insights about cerebellar response to inflammation and natural history of its liquefactive necrosis.

\section{Patient's perspective}

I was so scared when my baby acutely deteriorated last year after the bouts of loose motions. Although the doctors saved her life with the tube in her neck and other life-support systems, no exact cause was revealed in any of the lab tests. Thankfully, my baby has been significantly improving. I am told the abnormal patches in her hindbrain seen on MRI have also not worsened, but need to be followed up. I hope for her full recovery and near-normal development. 


\section{Learning points}

Isolated non-progressive bilaterally symmetrical postinfective cerebellar necrosis in a child is an extremely rare clinical entity which needs a detailed workup to rule out probable causative factors.

- The topographical and chronological distribution of the involvement in the absence of abnormal contrast enhancement provide important imaging clues to the differential diagnoses.

- Clinicoradiological follow-up in such cases may provide newer insights into the management of inciting neurological insult.

Contributors BH: imaging protocol and monitoring, image analysis, literature review and preparation of initial draft of manuscript. SV: concept and design of the study, analysis of the radiological data, critical review of manuscript, and final approval of the version to be published. SV will act as guarantor for this paper. LS: patient management, critical review of manuscript for important intellectual content. SK: literature review and contribution to the draft of the manuscript.

Funding The authors have not declared a specific grant for this research from any funding agency in the public, commercial or not-for-profit sectors.

Competing interests None declared.

Patient consent for publication Parental/guardian consent obtained.

Provenance and peer review Not commissioned; externally peer reviewed.

\section{REFERENCES}

1 Ashdown BC, Boyko OB, Uglietta JP, et al. Postradiation cerebellar necrosis mimicking tumor: MR appearance. J Comput Assist Tomogr 1993;17:124-6.

2 Peng $\mathrm{JH}$, Feng $\mathrm{Y}$, LeBlanc $\mathrm{MH}$, et al. Apoptosis and necrosis in developing cerebellum and brainstem induced after focal cerebral hypoxic-ischemic injury. Brain Res Dev Brain Res 2005; 156:87-92.

3 Ricci A, Di Vitantonio H, De Paulis D, et al. Systemic sclerosis associated with colliquative necrosis in the cerebellum. Surg Neurol Int 2017;8:44.

4 Wells AL. Cerebellar necrosis in a case of subarachnoid haemorrhage. $\mathrm{Br}$ Med J 1953;2:1356-7.

5 Canavese C, Davico C, Casabianca M, et al. Bilateral Striatal Necrosis after Sydenham's Chorea in a 7-Year-Old Boy: A 2-Year Follow-Up. Neuropediatrics 2018;49:209-12.

Copyright 2019 BMJ Publishing Group. All rights reserved. For permission to reuse any of this content visit

https://www.bmj.com/company/products-services/rights-and-licensing/permissions/

BMJ Case Report Fellows may re-use this article for personal use and teaching without any further permission.

Become a Fellow of BMJ Case Reports today and you can:

- Submit as many cases as you like

- Enjoy fast sympathetic peer review and rapid publication of accepted articles

- Access all the published articles

- Re-use any of the published material for personal use and teaching without further permission

\section{Customer Service}

If you have any further queries about your subscription, please contact our customer services team on +44 (0) 2071111105 or via email at support@bmj.com.

Visit casereports.bmj.com for more articles like this and to become a Fellow 